\title{
How Robust Are Trends in the Brewer-Dobson Circulation Derived from Observed Stratospheric Temperatures?
}

\author{
AlBert OSSÓ AND YOLANDA SOLA \\ Department of Astronomy and Meteorology, University of Barcelona, Barcelona, Spain \\ KAREN ROSENLOF \\ Chemical Sciences Division, NOAA/Earth System Research Laboratory, Boulder, Colorado \\ BIRGIT HASSLER \\ Chemical Sciences Division, NOAA/Earth System Research Laboratory, and Cooperative Institute for \\ Research in Environmental Sciences, University of Colorado, Boulder, Colorado \\ JOAN BECH AND JERÓNIMO LORENTE \\ Department of Astronomy and Meteorology, University of Barcelona, Barcelona, Spain
}

(Manuscript received 15 April 2014, in final form 30 December 2014)

\begin{abstract}
Most global circulation models and climate-chemistry models forced with increasing greenhouse gases predict a strengthening of the Brewer-Dobson circulation (BDC) in the twenty-first century, and some of them claim that such strengthening has already begun at the end of the twentieth century. However, observational evidence for such a trend remains inconclusive. The goal of this paper is to examine the evidence for observed trends in the stratospheric overturning circulation using a suite of currently available observational stratospheric temperature data. Trends are examined as "departures" from the global mean temperature, since such trends reflect the effects of dynamics and spatially inhomogeneous radiative forcing and are to first order independent of the direct radiative effects of increasing well-mixed greenhouse gas concentrations.

The primary conclusion of the study is that temperature observations do not reveal statistically significant trends in the Brewer-Dobson circulation over the period from 1979 to the present, as covered by Microwave Sounding Unit and Stratospheric Sounding Unit temperatures. The estimated trends in the BDC are weak in all datasets and not statistically significant at the $95 \%$ confidence level. In many cases, different data products yield very different results, particularly when the trends are stratified by season. Implications for the interpretation of recent stratospheric climate change are discussed. The results illustrate the essential need to better constrain the accuracy of future stratospheric temperature datasets.
\end{abstract}

\section{Introduction}

The Brewer-Dobson circulation (BDC; Dobson et al. 1929; Brewer 1949; Dobson 1956) is a slow, hemisphericscale, meridional overturning circulation in the stratosphere, with air moving upward in the tropics and poleward and downward at higher latitudes. The BDC consists of a "shallow" branch, a strong circulation

Corresponding author address: Albert Ossó, Astronomy and Meteorology, University of Barcelona, Martí i Franquès 1, E-08028 Barcelona, Spain.

E-mail: aosso@am.ub.es driven by wave breaking in the lower stratosphere, juxtaposed on a "deep" branch, a weaker circulation driven by planetary waves breaking in the middle and upper stratosphere (Plumb 2002; Birner and Bönisch 2011). The main physical mechanism driving the BDC is the deposition of easterly momentum in the stratosphere due to wave breaking producing a body force resulting in a poleward mass flow. Mass continuity in an atmosphere with density decreasing with height requires that the poleward flow be accompanied by upwelling in the tropics and downwelling at higher latitudes (e.g., Holton et al. 1995; Haynes et al. 1991). The vertical motion drives stratospheric temperatures away from 
radiative equilibrium, below near the tropical tropopause and in the higher-latitude downwelling regions (Holton et al. 1995). BDC strength varies seasonally, with stronger cells in the winter hemisphere (Rosenlof 1995). Moreover, because of the differences in wave activity between the two hemispheres, the annual average BDC is stronger in the Northern Hemisphere (NH) than it is in the Southern Hemisphere (SH) (Yulaeva et al. 1994).

The BDC is a prominent dynamical phenomenon in the stratosphere and affects physical and chemical processes. Most significantly, it transports trace gases meridionally and vertically. These include ozone, which absorbs nearly all of the biologically harmful highly energetic ultraviolet radiation and impacts the radiative balance in the stratosphere. The BDC moves ozone-rich air from the tropical production region to middle and high latitudes and transports ozone depleting substances throughout the stratosphere, thereby playing a role in residence times of chemicals in the atmosphere. (Solomon 1999; WMO 2012, and references therein).

Recent studies suggest that climate change may also play a prominent role in long-term variations of the BDC [an excellent review is provided by Butchart (2014)]. The first suggestion of the BDC response to climate change was presented by Rind et al. (1990) based on a doubled $\mathrm{CO}_{2}$ global circulation model (GCM) experiment. The $\mathrm{CO}_{2}$ doubling leads to improved propagation conditions for planetary waves and increased gravity wave drag that helps to intensify the circulation. A number of subsequent studies (e.g., Butchart and Scaife 2001; Austin 2002; Sigmond et al. 2004; Butchart et al. 2006; McLandress and Shepherd 2009; Butchart et al. 2010; Lin and Fu 2013) using GCM and climate-chemistry model (CCM) simulations forced with increasing greenhouse gas (GHG) concentrations also found an acceleration of the BDC due to increased wave penetration into the stratosphere. Some studies report that the predicted BDC strengthening is also apparent in the simulations of the recent past. Austin (2002) using a CCM forced with the observed history of GHG concentrations found an increase of the tropical upward mass flux for the 1980-2000 period of about 3\% $\pm 2 \%$ decade $^{-1}$ in the lower stratosphere that increased to up to $10 \% \pm 8 \%$ decade $^{-1}$ in the upper stratosphere. $\mathrm{Li}$ et al. (2008) using also a CCM simulation forced with the observed history of GHG concentration found an increase of tropical upwelling about $4.3 \% \pm 0.75 \%$ decade $^{-1}$ during the 1975-99 period. Garcia et al. (2007) found in a CCM retrospective simulation of the late twentieth century (1950-2003) a significant decrease of the stratospheric age of air of $2 \%$ decade $^{-1}$, indicative of an acceleration of the BDC. The simulated trend in the
BDC has raised interest in stratospheric climate change, and it highlights the critical need for high-quality observations to validate model simulation.

The modeled increases in the tropical upward mass flux associated with the BDC are believed to be due to changes in the penetration of tropospheric wave forcing into the stratosphere due to GHG concentration increase. However, the mechanisms for such changes are not well understood. Butchart et al. (2010), using a large number of model simulations with comparable emission scenarios, found an increase in the annual mean tropical upwelling in the lower stratosphere of about $2 \%$ decade $^{-1}$ throughout the twenty-first century, of which $\sim 60 \%$ was forced by parameterized orographic gravity wave drag. Increases in orographic wave drag in the lower stratosphere are considered a robust model response to GHG concentration increase resulting from the eastward acceleration of the subtropical jets (Li et al. 2008; McLandress and Shepherd 2009; Butchart et al. 2010). Other studies suggest that $\sim 60 \%$ of the net upward mass flux trend is a consequence of increased planetary wave drag (McLandress and Shepherd 2009). Calvo and Garcia (2009) concluded that enhanced dissipation of quasi-stationary planetary waves forced by increased tropical convection is responsible for the upwelling trends.

If the simulated strengthening of the BDC were to actually occur, it would change the distribution of chemical species in the stratosphere due to both transport changes and temperature changes impacting chemistry. Ozone would decrease in the tropics and increase at midlatitudes in the lower stratosphere. Shepherd (2008) showed a modeled super-recovery of total ozone in the NH midlatitudes and a decrease in the tropics due to changes in the lower stratospheric ozone distribution in the second half of the twenty-first century as a consequence of a strengthening BDC. Stratospheric ozone redistribution could also affect tropospheric ozone by changing the penetration of ultraviolet radiation into the troposphere, thus potentially affecting photolysis rates (Hegglin and Shepherd 2009; WMO 2011), as well as changing stratosphere-to-troposphere transport of ozone at middle to high latitudes.

Observational support for the simulated strengthening of the BDC remains elusive (Butchart 2014). Because BDC strength is not a directly observable quantity, inferences from species measurements or calculations from reanalysis are required. The strength of the BDC is assessed in many modeling- and reanalysisbased studies through estimates of tropical upwelling or meridional mass transport. In practice, both quantities are very difficult to diagnose directly from meteorological observations (Seviour et al. 2012). As such, 
essentially all observational studies of trends in the BDC rely on indirect measurements of the strength of the BDC. Engel et al. (2009) analyzed balloon-borne measurements of stratospheric trace gases and argued that the resulting trends in the mean age of air in the stratosphere do not support any significant long-term trend in the $\mathrm{NH}$ branch of the BDC over the past $\sim 30$ years. Their results differ from model simulations of the recent past that suggest decreasing trends of the stratospheric mean age (Austin and Li 2006; Austin et al. 2007; Garcia et al. 2007; Garcia and Randel 2008), although the simulated trends are within the error bars of the Engel et al. (2009) results. However, Ray et al. (2010), using stratospheric constituent data and a simple tropical pipe model, show that midlatitude/tropical mixing trends may also impact age of air trends, and theoretically could bring trends observed from observations into agreement with an increasing BDC. Cook and Roscoe (2009) concluded that there has been any significant trend in the BDC over the Southern Hemisphere since 1990 based on analysis of $\mathrm{NO}_{y}$ measurements over Antarctica. Thompson and Solomon (2009) analyzed the meridional structure of ozone column and lowerstratosphere temperatures from observations and concluded that the meridional structure of the ozone trends is consistent with a strengthening of the BDC since the late 1970s. Lin et al. (2009) found increasing extratropical temperatures in the $\mathrm{SH}$, indicative of a strengthening of the BDC. Fu et al. (2010) presented evidence that the seasonality of tropical lower-stratospheric temperature trends is a consequence of changes in the BDC driven by extratropical wave forcing.

Reanalysis fields have also been used to diagnose the strength of the BDC. Iwasaki et al. (2009), analyzing the BDC from five reanalyses, concluded that, although the climatological mean states are consistently captured by reanalysis, the yearly trends are not reliable due to the large discrepancies between results derived from the different reanalyses. Seviour et al. (2012), using the European Centre for Medium-Range Weather Forecasts (ECMWF) interim reanalysis (ERA-Interim; Dee et al. 2011), showed a decrease in the upwelling mass flux in contrast to the increase projected by models, even though the reanalysis reproduced the major features of the BDC. On the other hand, Garny et al. (2011) found agreement between modeled tropical upwelling and its wave forcing and that in ERA-Interim.

Because the BDC is associated with large-scale variations in vertical motion, temperature measurements can be used to infer changes in the strength of the BDC. Young et al. (2012) provided the most comprehensive study to date of observationally based trends in the BDC using both Microwave Sounding Unit (MSU) and
Stratospheric Sounding Unit (SSU) observational stratospheric temperature data. The authors exploited the relationship between tropical and extratropical temperatures and the interannual variation in circulation's strength (Ueyama and Wallace 2010; Young et al. 2011) to empirically derive an adjusted temperature-based BDC index $\left(\mathrm{BDCI}^{\mathrm{adj}} \mathrm{T}\right)$ over 1979-2005. Their results are consistent with a strengthening of the $\mathrm{NH}$ branch of the BDC during December throughout the depth of the stratosphere, and with a significant strengthening of the $\mathrm{SH}$ branch of the BDC during August from the MSU channel 4 (MSU4) level to the midstratosphere SSU channel 2 (SSU2) level. They also found a significant weakening of the NH BDC branch during March that is consistent with a change in the seasonal cycle of the circulation. Fu et al. (2010) noted that similar high-latitude cooling found in MSU4 during March is consistent with a weakening of the BDC in the $\mathrm{NH}$ spring.

The results shown by Young et al. (2012) in the middle and upper stratosphere are based entirely on a version of the SSU data produced by the Met Office (the dataset is hereafter referred to as Met Office-SSU). In 2012, the National Oceanic and Atmospheric Administration (NOAA) Center for Satellite Applications and Research (STAR) group published a new version of theSSU dataset (hereafter referred to as NOAA-SSU) (Wang et al. 2012). As noted by Wang et al. (2012) and Thompson et al. (2012), stratospheric temperature trends derived from the NOAA-SSU and the previous Met Office-SSU datasets yield strikingly different results. This is true not only in terms of the global-mean trends, but also in terms of the latitudinal structure of the temperature trends. The marked differences between the Met Office and NOAA versions of the SSU data suggest that the observed trends in the BDC may differ significantly from one SSU dataset to another.

In this study, we also examine BDC trends using temperature data, but using an different methodology than in Young et al. (2012) and Fu et al. (2010). In particular, we examine trends in the zonal temperature departures from the global mean (see section 3). To first order, changes in global mean temperature do not reflect changes in circulation because, considering the global averages, cooling associated with upward motion in the tropics is largely compensated by warming resulting from downward motion in the extratropics (Yulaeva et al. 1994). The global average change therefore reflects primarily the radiative effects of the well-mixed GHG concentration increase. If the BDC speeds up we expect its signature to be reflected in the meridional structure of this "departure field" (see section 3).

The purpose of this paper is to use this methodology to revisit the observational evidence of the strengthening 
of the BDC over the past few decades using a suite of currently available satellite and radiosonde temperature measurements.

\section{Data}

\section{a. Satellite data}

We analyze satellite brightness temperature data from the MSU and SSU instruments, both of which are part of a series of consecutive NOAA operational polar-orbiting satellites. We use lower stratospheric data processed by Remote Sensing Systems (RSS; Mears and Wentz 2009), the University of Alabama-Huntsville (UAH; Christy et al. 2003) and NOAA STAR group (Zou et al. 2006) that combines channel 4 from MSU (MSU4) and channel 9 from the Advanced Microwave Sounding Unit (AMSU9) (hereafter referred as MSU4_RSS, MSU4_ UAH, and MSU4_NOAA respectively). The monthly mean brightness temperature is provided on a $2.5^{\circ} \times 2.5^{\circ}$ horizontal grid spanning from $82.5^{\circ} \mathrm{S}$ to $82.5^{\circ} \mathrm{N}$ from 1979 onward. MSU4 provides global coverage of temperature in an atmospheric layer between roughly 13 and $22 \mathrm{~km}$, covering mainly the lower stratosphere in the extratropics but also part of the upper troposphere in the tropics.

Channels 1, 2, and 3 (herein denoted as ch1, ch2, and ch3) of the SSU dataset have their weighting functions centered at altitudes of approximately 30,40 , and $45 \mathrm{~km}$, respectively, and have been used to analyze temperature in the middle and upper stratosphere. The SSU instrument consists of a pressure-modulated radiometer that senses temperature in the $15-\mu \mathrm{m}$ infrared $\mathrm{CO}_{2}$ band. The SSU data are the only long time near-global coverage source for temperature in the middle and upper stratosphere; the data are available from 1979 to 2005. The temperatures derived from the different SSU channels have been analyzed in previous studies to assess stratospheric temperature trends (e.g., Nash and Forrester 1986; Ramaswamy et al. 2001; Shine et al. 2003; Randel et al. 2009). However, the use of the SSU data for climate studies requires consideration of specific calibration issues. These issues include the following: 1) Gas leaking has occurred in all SSU pressure cells over time, causing changes in the altitude being measured by the instrument; 2) at high altitudes, the diurnal and semidiurnal tidal variations become large, and thus satellite orbital drift and orbital changes between the different satellite missions can lead to large biases in temperature; 3 ) long-term changes in carbon dioxide concentrations have led to an upward drift of the satellite weighting functions with time (Shine et al. 2008); and 4) some consecutive satellite missions do not have overlapping measurements to facilitate the merging of the radiances.
Here we use two SSU temperature datasets that have been processed independently. The first dataset consists of corrected SSU brightness temperatures derived from the pioneering work conducted by scientists of the Met Office (Nash and Forrester 1986; Nash 1988) and then revised to take into account long-term increases in atmospheric $\mathrm{CO}_{2}$ (Shine et al. 2008). The Met Office-SSU temperature data are available as monthly zonal mean anomalies on a $10^{\circ}$ latitude grid covering from $70^{\circ} \mathrm{S}$ to $70^{\circ} \mathrm{N}$. The second dataset consists of SSU radiances recently reprocessed by the NOAA STAR group. The data are available on a $2.5^{\circ} \times 2.5^{\circ}$ horizontal grid covering from $87.5^{\circ} \mathrm{S}$ to $87.5^{\circ} \mathrm{N}$ for the period $1979-2005$. Details of the data processing are given by Wang et al. (2012).

The two SSU datasets provide a very different picture of the past stratospheric climate change. As shown by Thompson et al. (2012), the global mean channel 1 and 2 cooling trends derived from the SSU data are almost twice as large for the NOAA STAR product as they are for the Met Office product. Similarly pronounced differences are also found in the latitudinal structures of the trends between the two datasets, suggesting the two products will yield a very different picture of trends in the BDC.

\section{b. Radiosondes}

We use two radiosonde products to assess trends in the lower stratosphere. The Radiosonde Atmospheric Temperature Products for Assessing Climate B (RATPAC-B; Free et al. 2005) provides monthly mean temperature anomalies at 13 pressure levels from the surface to $30 \mathrm{hPa}$ for 85 globally distributed stations. The monthly means from 1958 to 1997 were adjusted by a team of climate scientists using a multifactor analysis without satellite data as references with minimal use of neighbor station comparisons [see Free et al. (2005) and references therein]. The dataset was extended with the Integrated Global Radiosonde Archive (IGRA; Durre et al. 2006) from 1997 onward without any adjustment for inhomogeneities. Free et al. (2005) calculated an uncertainty in global mean trends from 1979 to 2004 of less than $0.15 \mathrm{~K} \mathrm{decade}^{-1}$ in the stratosphere at individual pressure levels. The 0000 and 1200 UTC combined observations were binned into $10^{\circ}$ latitude bands to determine zonal mean temperature anomalies and subsequently the cosine-weighted global mean anomalies.

The second dataset is the Radiosonde Innovation Composite Homogenization product ( $\mathrm{RICH}$; Haimberger et al. 2012). RICH is built using more than 1000 daily station records from the global radiosonde network and it constructs the reference series for 
homogenization from composites of neighboring radiosonde station temperature anomalies. Therefore, its homogenization estimates are independent of the satellite data. RICH provides homogenized temperature anomalies at 10 discrete pressure levels ranging from 850 to $30 \mathrm{hPa}$ for the period $1958-2013$ on a $5^{\circ} \times 5^{\circ}$ horizontal grid resolution. The radiosonde data used in this study span from 1958 to 2013 at 70,50 , and $30 \mathrm{hPa}$ (i.e., the levels that lie within the vertical range of MSU and SSU1 instruments). Observations were binned into $10^{\circ}$ wide latitude bands to determine zonal mean temperature anomalies and subsequently the cosineweighted global mean anomalies.

\section{Inferring trends in the BDC from temperatures}

The BDC can be approximated from the transformed Eulerian mean (TEM) residual circulation, which provides an estimate of large-scale atmospheric transport. The linearized version of the TEM thermodynamic energy equation (Andrews et al. 1987) relates the stratospheric temperature tendency to the vertical motion due to the BDC:

$$
\frac{\partial \bar{T}}{\partial t}=-\alpha_{r}\left(\bar{T}-\overline{T_{r}}\right)-\overline{w^{*}} S,
$$

where $\partial \bar{T} / \partial t$ is the zonal-mean temperature tendency; $-\alpha_{r}\left(\bar{T}-\overline{T_{r}}\right)$ represents the relaxation of the temperature to a radiative equilibrium value $\overline{T_{r}}$ with a time scale $1 / \alpha_{r}$; and $\overline{w^{*}} S$ denotes the adiabatic cooling (warming) associated with the upward (downward) flow with transformed vertical velocity $\overline{w^{*}}$ and a static stability parameter $S$. The overbar denotes a zonal mean.

As demonstrated by Yulaeva et al. (1994), the out-ofphase seasonal cycle between extratropical and tropical mean temperatures reflects the seasonal cycle in adiabatic heating/cooling that is the result of the seasonal cycle in the strength of the BDC. They also showed that the month-to-month temperature changes in the tropics and extratropics are significantly anticorrelated, indicating compensation between compressional warming and expansional cooling. Moreover, they suggested that the observed out-of-phase seasonal cycles in the lower stratosphere temperature between the tropics and extratropics are controlled by the strength of the extratropical wave driving that forces the BDC.

Young et al. (2011) used the Met Office-SSU data to extend the analysis of Yulaeva et al. (1994) into the middle and upper stratosphere. They demonstrated that the out-of-phase relationship between tropical and extratropical stratospheric temperatures (which is indicative of variability in the BDC) also extends to the middle and upper stratosphere. The BDC has a very weak signature in the tendency in global mean temperatures, since regions of rising motion and adiabatic cooling are compensated by regions of sinking motion and adiabatic warming (Yulaeva et al. 1994; Rosenlof 1995). Hence, trends in the BDC should be most apparent in the meridional structure of the trends in the zonal-mean temperatures as opposed to global-mean stratospheric temperature trends themselves.

In this paper we examine the meridional structure of trends in a "temperature departure field" $T^{*}$ defined as

$$
T^{*}=\bar{T}-T_{\text {global }},
$$

where $\bar{T}$ is the monthly multiyear zonal-mean temperature anomaly and $T_{\text {global }}$ is the monthly multiyear cosine-weighted global mean temperature anomaly for the periods considered. Note that according to this definition $T^{*}$ is a zonally average magnitude. The global mean is determined for the whole domain covered by each dataset (Table 1). The zonal mean temperature anomalies are calculated subtracting the monthly longterm multiyear mean of each latitude band from the corresponding zonal mean. As stated before, trends in the global-mean temperatures reflect changes not in circulation but rather in the radiative effects of the wellmixed GHG concentration increase. Therefore, to first order, trends in the departure temperature field $T^{*}$ are not strongly affected by radiatively forced temperature trends due to changes in well-mixed greenhouse gases; instead, they reflect changes in circulation (which may be a consequence of changes in GHGs). Additionally, any forcing that includes a latitudinal gradient will also project into $T^{*}$; this includes Antarctic ozone depletion changing with time. The construction of the $T^{*}$ field is illustrated graphically in Fig. 1, using an example of the time series of December at $60^{\circ} \mathrm{N}$ from the NOAA-SSU channel 3.

To gain further insight, we calculate trends for a temperature-based BDC index (hereafter denoted BDCI_T) defined as the extratropical mean temperature anomalies of a given hemisphere minus the tropical mean temperature anomalies for each month:

$$
\text { BDCI_T }=T_{\text {extr }}-T_{\text {trop }} \text {. }
$$

Note that to compute the BDCI_T we use the zonal mean temperature anomalies instead of $T^{*}$ because if we assume that the radiative effect of well-mixed GHGs concentration increase is independent of latitude, then its effect over the BDCI_T trends is removed by construction when subtracting $T_{\text {trop }}$ from $T_{\text {extr }}$. 
TABLE 1. Description of the datasets used in this study. The vertical range for satellite data indicates the altitude bounds of the half power range around the peak of the corresponding weighting function.

\begin{tabular}{|c|c|c|c|c|c|c|}
\hline Satellite data & & $\begin{array}{l}\text { Data } \\
\text { period }\end{array}$ & $\begin{array}{l}\text { Spatial } \\
\text { resolution }\end{array}$ & Spatial domain & Vertical range & References \\
\hline NOAA-SSU & Monthly & 1979-2005 & $2.5^{\circ} \times 2.5^{\circ}$ & $82.5^{\circ} \mathrm{S}-82.5^{\circ} \mathrm{N}$ & $\begin{array}{l}\operatorname{ch} 1 \sim 25-35 \mathrm{~km} \\
\operatorname{ch} 2 \sim 35-45 \mathrm{~km} \\
\operatorname{ch} 3 \sim 40-50 \mathrm{~km}\end{array}$ & Wang et al. (2012) \\
\hline Met Office-SSU & Monthly & 1979-2005 & $\begin{array}{l}10^{\circ} \text { wide latitude } \\
\text { bands }\end{array}$ & $70^{\circ} \mathrm{S}-70^{\circ} \mathrm{N}$ & $\begin{array}{l}\operatorname{ch} 1 \sim 25-35 \mathrm{~km} \\
\operatorname{ch} 2 \sim 35-45 \mathrm{~km} \\
\operatorname{ch} 3 \sim 40-50 \mathrm{~km}\end{array}$ & $\begin{array}{l}\text { Nash and Forrester } \\
\text { (1986) }\end{array}$ \\
\hline MSU4 RSS & Monthly & 1979-2013 & $2.5^{\circ} \times 2.5^{\circ}$ & $88.75^{\circ} \mathrm{S}-88.75^{\circ} \mathrm{N}$ & $\sim 15-20 \mathrm{~km}$ & Mears and Wentz (2009) \\
\hline MSU4 NOAA & Monthly & 1979-2013 & $2.5^{\circ} \times 2.5^{\circ}$ & $88.75^{\circ} \mathrm{S}-88.75^{\circ} \mathrm{N}$ & $\sim 15-20 \mathrm{~km}$ & Zou et al. (2006) \\
\hline $\begin{array}{l}\text { MSU4 UAH } \\
\text { Radiosonde data }\end{array}$ & Monthly & 1979-2013 & $2.5^{\circ} \times 2.5^{\circ}$ & $88.75^{\circ} \mathrm{S}-88.75^{\circ} \mathrm{N}$ & $\sim 15-20 \mathrm{~km}$ & Christy et al. (2003) \\
\hline RATPAC-B & Monthly & $1958-2013$ & $\begin{array}{l}10^{\circ} \text { wide latitude } \\
\text { bands }\end{array}$ & - & $\begin{array}{c}3 \text { discrete pressure levels } \\
(70,50, \text { and } 30 \mathrm{hPa})\end{array}$ & Free et al. (2005) \\
\hline $\mathrm{RICH}$ & Monthly & $1958-2013$ & $\begin{array}{l}10^{\circ} \text { wide latitude } \\
\text { bands }\end{array}$ & - & $\begin{array}{c}3 \text { discrete pressure levels } \\
(70,50, \text { and } 30 \mathrm{hPa})\end{array}$ & Haimberger et al. (2012) \\
\hline
\end{tabular}

Following the same assumption made by Young et al. (2012), a change in the strength of the BDC will be reflected in the temperature difference between the tropical and higher latitudes. That is, if the BDC speeds up, there will be more cooling in the tropics (upwelling branch) and more warming at high latitudes (downwelling branches of the BDC). Young et al. (2012) based the construction of the BDC index on the observations [described in Young et al. (2011)] for the bulk of the winter and spring seasons that the time series of extratropical temperatures is anticorrelated with the time series of tropical temperatures over the depth of the stratosphere. That is December-April for the NH and June-November for the SH. Positive trends in the BDCI_T indicate warming in the extratropics correlated with cooling in the tropics that would be expected with an increasing trend in strength of the BDC.

To construct their BDC index, Young et al. (2012) first calculated the tropical $\left(20^{\circ} \mathrm{S}-20^{\circ} \mathrm{N}\right)$ and extratropical $\left(>40^{\circ} \mathrm{N}\right.$ for $\mathrm{NH}$ and $>40^{\circ} \mathrm{S}$ for $\left.\mathrm{SH}\right)$ mean temperature anomalies for each month and then the regression coefficients between the detrended tropical and extratropical time series. The significant anticorrelation between tropical and extratropical temperatures was used to "remove" the common BDC-like interannual variability. Finally, the original time series were adjusted and a BDC index computed [Eqs. (4)-(6)]:

$$
\begin{aligned}
T_{\text {trop }}^{\text {adj }} & =T_{\text {trop }}-r_{1} T_{\text {extr }}^{\prime}, \\
T_{\text {extr }}^{\text {adj }} & =T_{\text {extr }}-r_{2} T_{\text {trop }}^{\prime}, \quad \text { and } \\
\mathrm{BDCl}^{\text {adj }} \mathrm{T} & =T_{\text {extr }}^{\text {adj }}-T_{\text {trop }}^{\text {adj }},
\end{aligned}
$$

where "trop" and "extr" subscripts refer to tropical and extratropical; $T^{\text {adj }}, T^{\prime}$, and $T$ correspond to adjusted, detrended, and original temperature time series, and $r_{1}$ and $r_{2}$ are the regression coefficients for the tropics against extratropics and extratropics against tropics, respectively. We use $\mathrm{BDCI}^{\mathrm{adj}}{ }_{-} \mathrm{T}$ to refer to the adjusted BDC index described by Young et al. (2012). Here we argue that the adjustment removing the "BDC like" variability resulted in unrealistically significant trends and hence trends in the BDC should be viewed examining the nonadjusted BDCI_T [Eq. (3)] (hereafter BDCI_T stands for nonadjusted BDC index or temperature-based BDCI).

To test the ability of the BDCI_T to capture the temporal evolution of the BDC we use the output from the Whole Atmosphere Community Climate Model (WACCM) (Garcia et al. 2007, and references therein) to compare trends in the BDCI_T to trends in a newly defined index based on the TEM residual vertical velocity $\left(\overline{W^{*}}\right)$. The TEM diagnosis is based on an ensemble mean of four WACCM simulations forced with the time history of anthropogenic emissions prepared for the second phase of the Chemistry-Climate Model Validation project (CCMVal2) archive (Eyring et al. 2010).

We assume that the TEM-based index more faithfully represents the "real" BDC:

$$
\text { BDCI_W* }=W_{\text {extr }}^{*}-W_{\text {trop }}^{*},
$$

where $W_{\text {extr }}^{*}$ is the extratropical (from $40^{\circ}$ to $80^{\circ}$ latitude in the $\mathrm{NH}$ or in the SH depending on the month) $\bar{W}^{*}$ is the weighted mean, and $W_{\text {trop }}^{*}$ is the tropical $\left(20^{\circ} \mathrm{S}-\right.$ $\left.20^{\circ} \mathrm{N}\right) \overline{W^{*}}$ weighted mean. Note that this test does not provide a quantitative comparison between trends. The main purpose is to compare their overall behavior so the 
Zonal mean temperature anomalies at $60^{\circ} \mathrm{N}$

a)

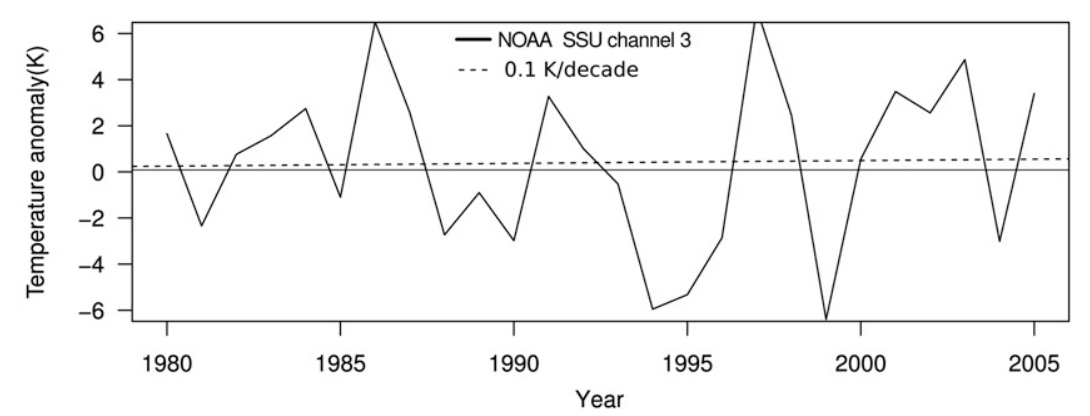

b)

Global mean temperature anomalies

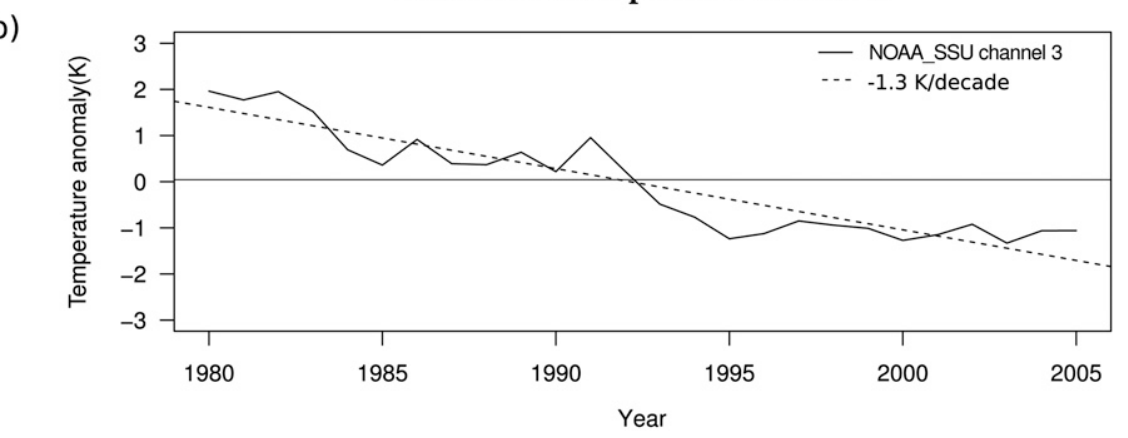

c)

Zonal mean minus global mean temperature anomalies at $60^{\circ} \mathrm{N}$

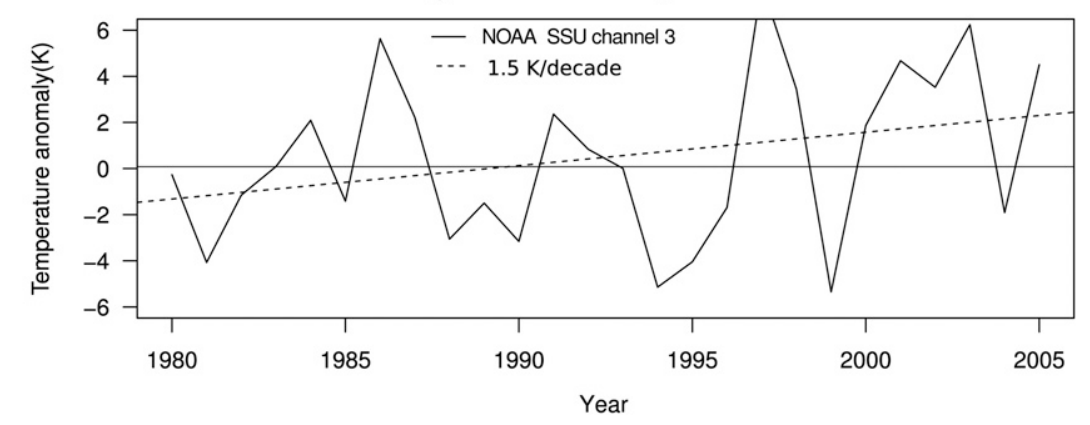

FIG. 1. Example of the construction of the temperature departure field $T^{*}$ using a time series of Decembers from the SSU channel 3 data. (a) Series of the zonal-mean temperature anomalies at $60^{\circ} \mathrm{N}$ and trend. (b) Series of global-mean temperature anomalies and trend. (c) Series of the departure field $T^{*}$ calculated as (a), (b) and trend. Solid lines are the raw temperature anomalies and dashed lines indicate the linear trend.

units of the BDCI_W* trends have been chosen to facilitate visual comparison.

Figure 2 shows the trends in BDCI_W* and BDCI_T for each month at $70 \mathrm{hPa}$; to facilitate their comparison, the sign of BDCI_W* has been reversed. A positive trend in the strength of the BDC would lead to a negative trend in the BDCI_W* (increased downwelling in the extratropics linked with increased upwelling in the tropics) and a positive trend in the BDCI_T. According to Fig. 2, trends in the BDCI_W* and BDCI_T match reasonably well (with a year-round correlation coefficient $r$ of 0.71 ) from June to September in the $\mathrm{SH}$ and from December to February in the $\mathrm{NH}$, hence suggesting that at least during those months the BDCI_T can be used to infer trends in the BDC. However, the indices show opposite signed trends during November in the SH and during March-April in the $\mathrm{NH}$; thus, BDCI_T seems inadequate to infer trends in the BDC in those months. The months where the BDCI_W* and BDCI_T behave differently coincide with the timing of maximum ozone depletion in the $\mathrm{SH}$ (OctoberNovember) and when there is the possibility of ozone depletion in the extratropical NH (March-April). We also compare the trends for the extratropical and tropical 
a)

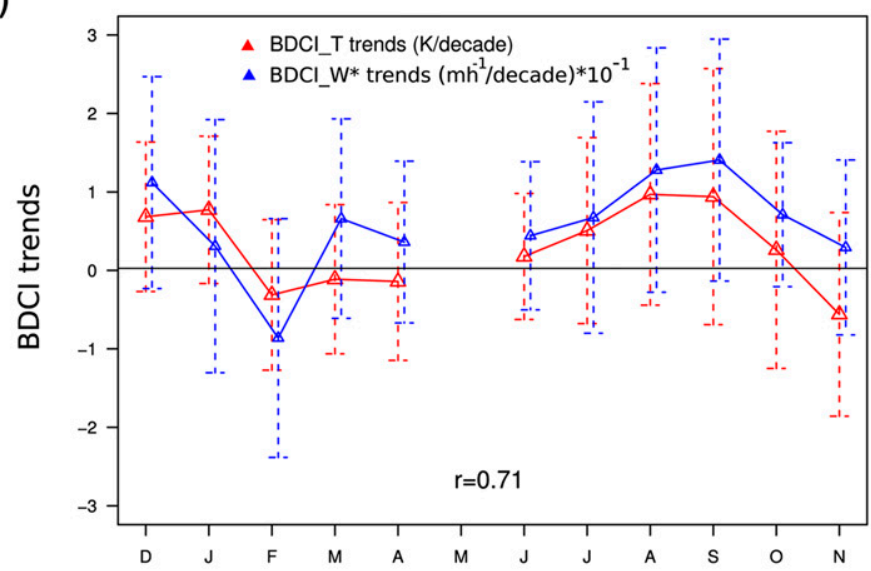

b)

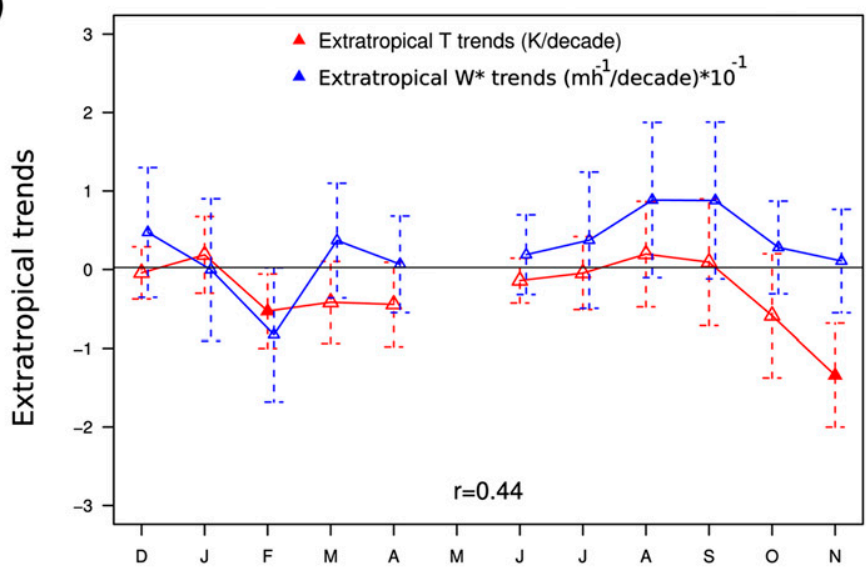

c)

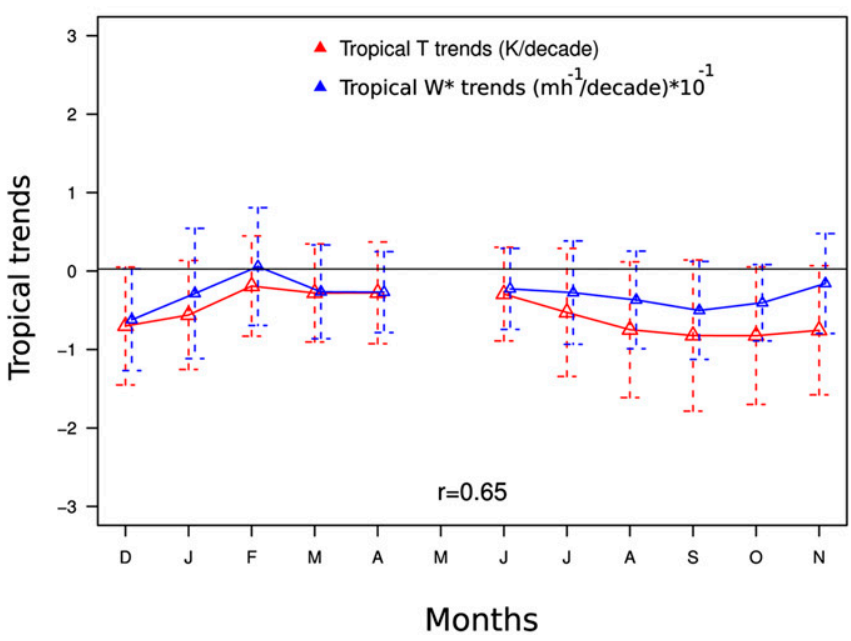

FIG. 2. BDCI_T and BDCI_W* trends calculated from (a) monthly BDCI_T trends and BDCI_W* trends at $70 \mathrm{hPa}$ for the WACCM model ensemble mean for the period 1979-2005 (the sign of BDCI_W* has been reversed to facilitate comparison). (b) Monthly extratropical mean $T^{*}$ and $W^{*}$ trends at $70 \mathrm{hPa}$ for the WACCM model for the period 1979-2005. (c) Monthly tropical mean $T^{*}$ and $W^{*}$ trends at $70 \mathrm{hPa}$ for the WACCM model for the period 1979-2005. Note that from December to April the BDCI_T trends are computed for the $\mathrm{NH}$ and from June to November for the $\mathrm{SH}$. May has been excluded from the analysis because extratropical temperatures are well anticorrelated with the tropical ones both in the $\mathrm{NH}$ and in the $\mathrm{SH}$. Error bars show the $95 \%$ confidence intervals. 
temperature means with the trends for $W_{\text {extr }}^{*}$ and $W_{\text {trop }}^{*}$ (Figs. 2b,c) to determine geographical and seasonal discrepancies between temperature variations and circulation variations. Figures $2 b$ and $2 c$ show that the trends in the temperature and $\overline{W^{*}}$ means differ in the extratropics $(r=0.44)$ but behave more similarly in the tropics $(r=0.65)$. Those results suggest that BDCI_T needs to be interpreted carefully during months with strong ozone depletion at high latitudes.

Trends for the departure temperature field $T^{*}$ and for BDCI_T are calculated using least squares linear regression applied to monthly-mean binned temperature data for the different time periods covered by each dataset (Table 1). Data from June 1991 to December 1992 and from April 1982 to December 1982 are excluded from the analysis to avoid potential influences on the trends due to the transient warming after the El Chichón and Pinatubo eruptions in 1982 and 1991, respectively. The significance of the trends was assessed using the methodology outlined by Santer et al. (2000) that accounts for the autocorrelation of the series.

\section{Results}

\section{a. Temperature trends in satellite data}

Figure 3 displays the temperature departure field $T^{*}$ trends as a function of month and latitude for the three layers sampled by the SSU instruments (from 25 to $50 \mathrm{~km}$ ). The left column shows results for the NOAASSU data; the right column results for the Met OfficeSSU data. As discussed in section 3, the observed trends are to first order linearly independent of changes in wellmixed GHG concentrations, and primarily reflect changes due to either 1) dynamics and/or 2) spatially inhomogeneous radiative forcing, such as that due to the ozone hole.

The three NOAA-SSU channels all show marked cooling in the tropical stratospheric $T^{*}$ that is juxtaposed against warming both in the $\mathrm{NH}$ and in the $\mathrm{SH}$ polar regions during December and during $\mathrm{SH}$ winter, respectively. Although the distinct meridional structure in the trends is consistent with a strengthening of the upper branch of the BDC in both hemispheres during the winter season in the last three decades, trends are not statistically significant for most of the channels. Only some seasonal $T^{*}$ trends at the top of the stratosphere (ch3) are significant at a $2 \sigma$ level at high latitudes during summer months in both hemispheres and during equinox months in the $\mathrm{SH}$. The lack of significance is attributable to the large interannual variability of highlatitude temperatures compared with relatively small trends. The BDC itself is a zonally averaged construct, but the polar night jet is wavy. The ozone depletion in the $\mathrm{SH}$ is effectively confined poleward of the polar jet, and this causes a radiative temperature signal due to changes in ozone that are not zonally uniform hampering the detection of the BDC signal in the temperature field.

For the NOAA-SSU retrieval, $T^{*}$ decreases over time at high $\mathrm{NH}$ latitudes during January-February for ch3 and during February-March for ch2 and ch1. The cooling of the $\mathrm{NH}$ polar cap during midwinter can only be partially explained by radiative cooling from ozone loss because the Arctic ozone depletion is much smaller than that in the Antarctic (Randel and Wu 1999; Solomon 1999). Moreover, the cooling of the NH polar cap during January-February is paired with weak warming over the subtropics that indicate a possible dynamical contribution to the observed cooling. Fu et al. (2010) noted that similar cooling, found in MSU4, is consistent with a weakening of the BDC in the NH spring. Nevertheless, neither the high-latitude cooling nor the weak tropical warming is statistically significantly different from zero.

The Met Office-SSU dataset yields a very different picture of recent stratospheric temperature trends. The trend pattern of Met Office-SSU3 is characterized by a year-round warming trend centered at $40^{\circ} \mathrm{S}$ and $40^{\circ} \mathrm{N}$ that is most marked in winter months. These warming trends in the departure temperature field are in agreement with the minimum cooling in the Met Office-SSU3 temperatures reported by Randel et al. (2009) and Young et al. (2012), except we have removed the effect of trends in well-mixed GHGs. The out-of-phase pattern of the trends between tropical and polar latitudes observed in NOAA-SSU3 data is not apparent during any month. The Met Office-SSU2 data show a very weak cooling in the tropics that is juxtaposed against a weak warming over $\mathrm{SH}$ during austral winter and against a weak warming in the $\mathrm{NH}$ polar cap during December. The same warming pattern, although weaker, is derived from Met Office-SSU1 data at high latitudes in the winter hemisphere but no simultaneous tropical cooling is detected. Virtually no zonal Met Office-SSU data-derived trend is statistically different from zero.

The same seasonal and latitudinal analysis of the departure field $T^{*}$ is performed for the three MSU4 products that sense the lower stratosphere $[\sim(15-$ $20 \mathrm{~km}$ )] (Fig. 4). The MSU4 temperature trends show a high-latitude warming centered on December-January in the $\mathrm{NH}$ and a weak warming in the $\mathrm{SH}$ during August-September that are not linked with any tropical cooling. In the $\mathrm{SH}$, temperature trends show a strong 
NOAA SSU
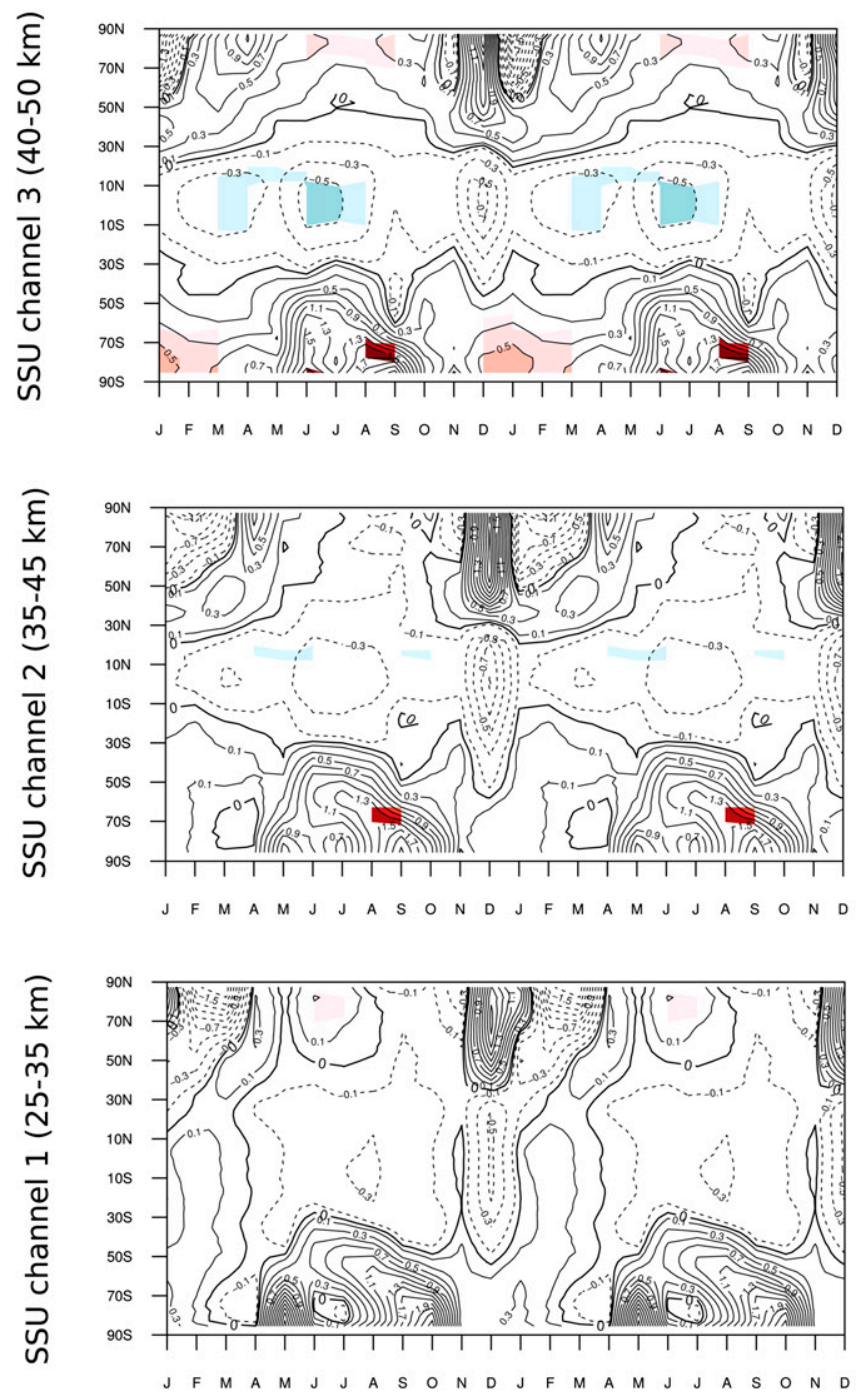

MetOffice SSU

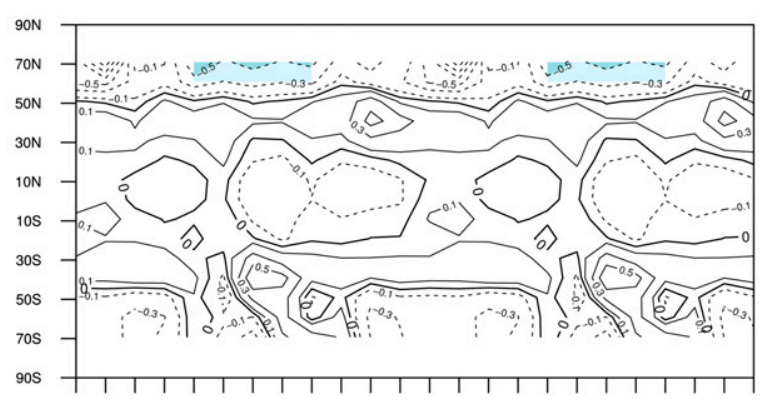

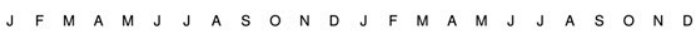
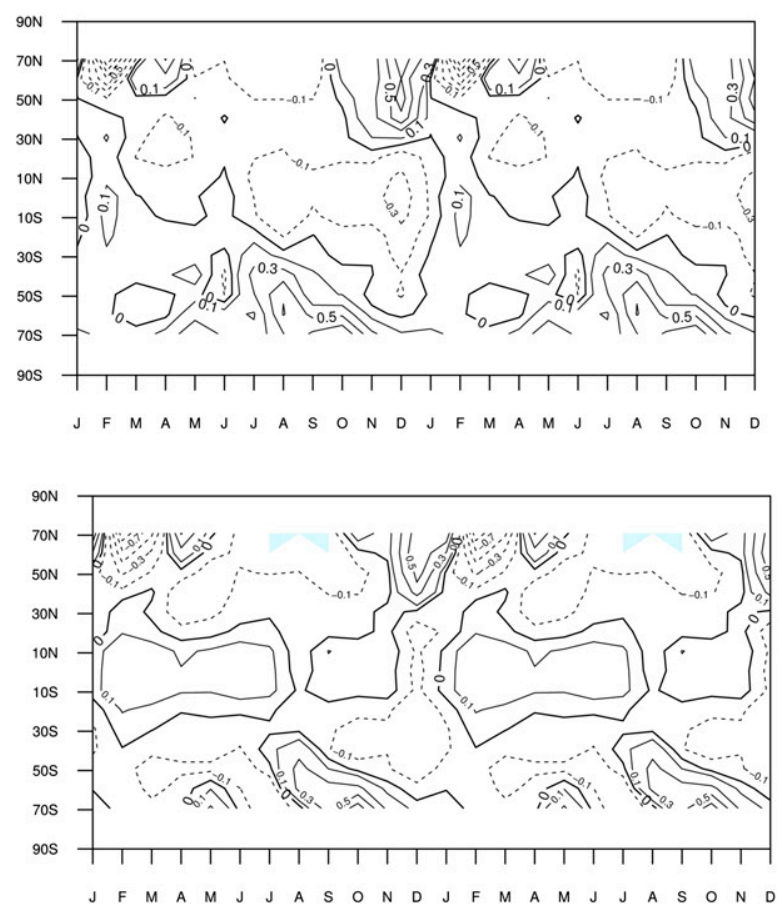

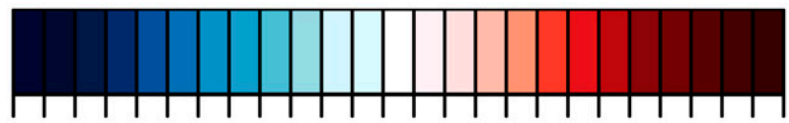

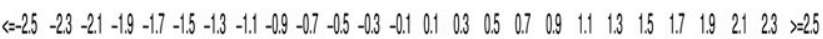

\section{(K/decade)}

FIG. 3. Zonal-mean $T^{*}$ trends as a function of month and latitude for (top)-(bottom) the three channels sampled by (left) the NOAA and (right) Met Office SSU products. Trends are computed for the 1979-2005 time period. Shaded regions show temperature trends statistically significant at the $95 \%$ confidence level. Note that we show two complete yearly cycles for clarity.

cooling of more than $-1.4 \mathrm{~K}$ decade $^{-1}$ centered on November-December that is attributable to the late spring radiative ozone cooling. Lin et al. (2009) pointed out that the near-zero trend in October is a consequence of temperature zonal asymmetries in the $\mathrm{SH}$ high latitudes that almost cancel the zonal mean trend; meanwhile, the radiatively induced ozone cooling overwhelms the dynamical warming. In any case, zonal mean trends in the lower stratosphere are not statistically significant at the $95 \%$ confidence level.

Figure 5 shows BDCI_T trends computed from December to April in the $\mathrm{NH}$ and from June to November in the SH. Statistically significant BDCI_T trends are represented with filled triangles and nonsignificant ones 
MSU4 RSS (15-20 km)

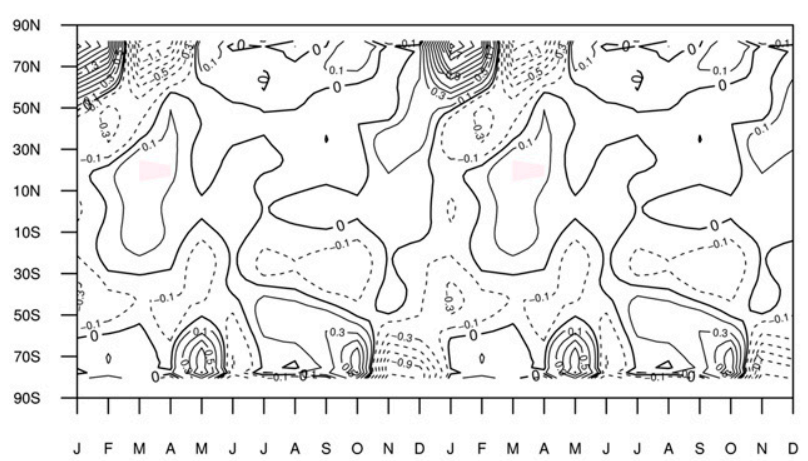

MSU4 NOAA (15-20 km)

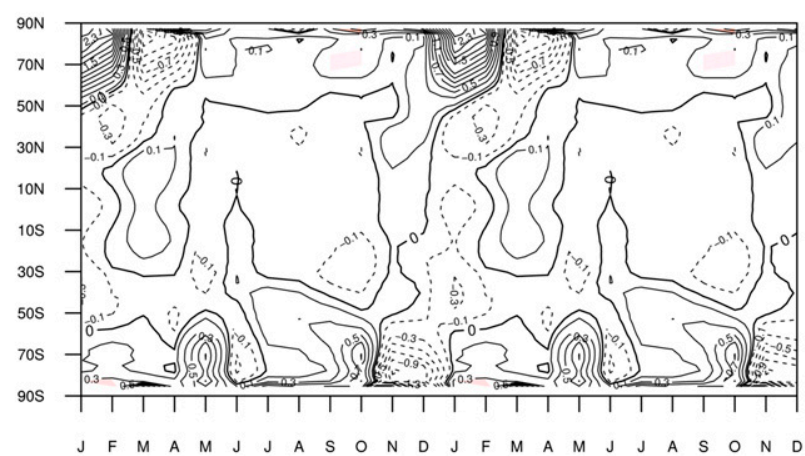

MSU4 UAH (15-20 km)

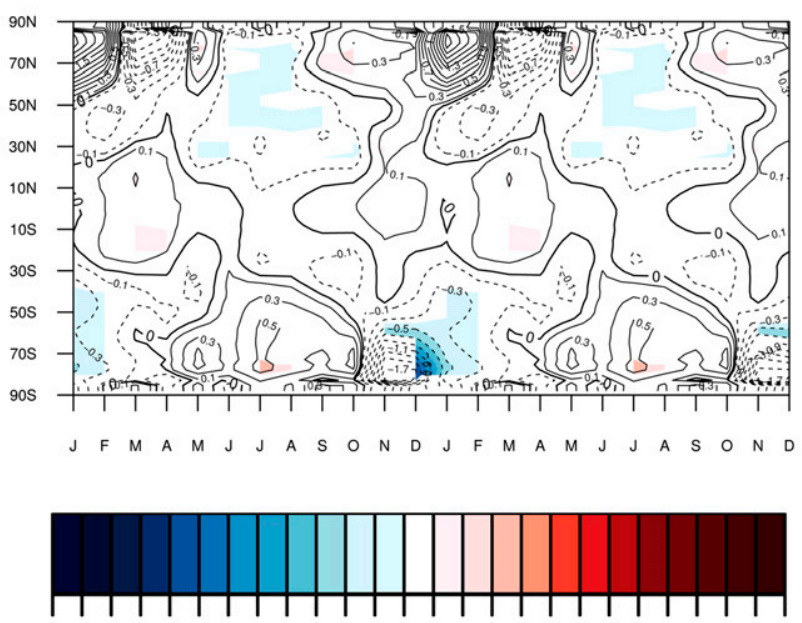

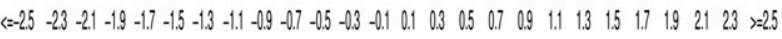

(K/decade)

FIG. 4. Zonal-mean $T^{*}$ trends as a function of month and latitude for the layer sampled by the three MSU4 products (MSU4_RSS, MSU4_UAH, and MSU4_NOAA). Trends are computed for the 1979-2013 time period. Shaded regions show temperature trends statistically significant at the $95 \%$ confidence level. Note that we show two complete yearly cycles for clarity.

with open triangles. Shaded areas represent the upper and lower $95 \%$ confidence levels of the BDCI_T trends for each NOAA-SSU and Met Office-SSU channels and for the MSU4-RSS data. The interannual variance in the BDCI_T time series is larger than the trends for almost every month in each channel and hence the trends in the BDCI_T are not significant. The only exceptions are for NOAA-SSU3 in the SH during October and November and in the $\mathrm{NH}$ during April where the variance is smaller. Despite that, it is worthy to note that for all of the NOAA-SSU channels as well as for the MSU4 data, trends in the BDCI_T are significant and positive during December assuming a $90 \%$ significant level instead of the $95 \%$ level considered in this analysis.
Our methodology leads to different conclusions than found by Young et al. (2012) and Fu et al. (2010). Using temperature anomalies from the Met Office-SSU, the MSU4, and the Iterative Universal Kriging (IUK) radiosonde dataset (Sherwood et al. 2008), Young et al. (2012) show that the trends in the BDCI ${ }^{\text {adj }} \mathrm{T}$ are consistent with an acceleration of the $\mathrm{NH}$ branch of the BDC during December throughout the depth of the stratosphere. They found statistically significant positive trends in the BDCI ${ }^{\text {adj }}$ T $\mathrm{T}$ for January and February and a significant negative trend during March both in the MSU4 and the IUK datasets. In the SH they show significant positive trends during August from the MSU4 level to the SSU-ch2 level that may indicate an 

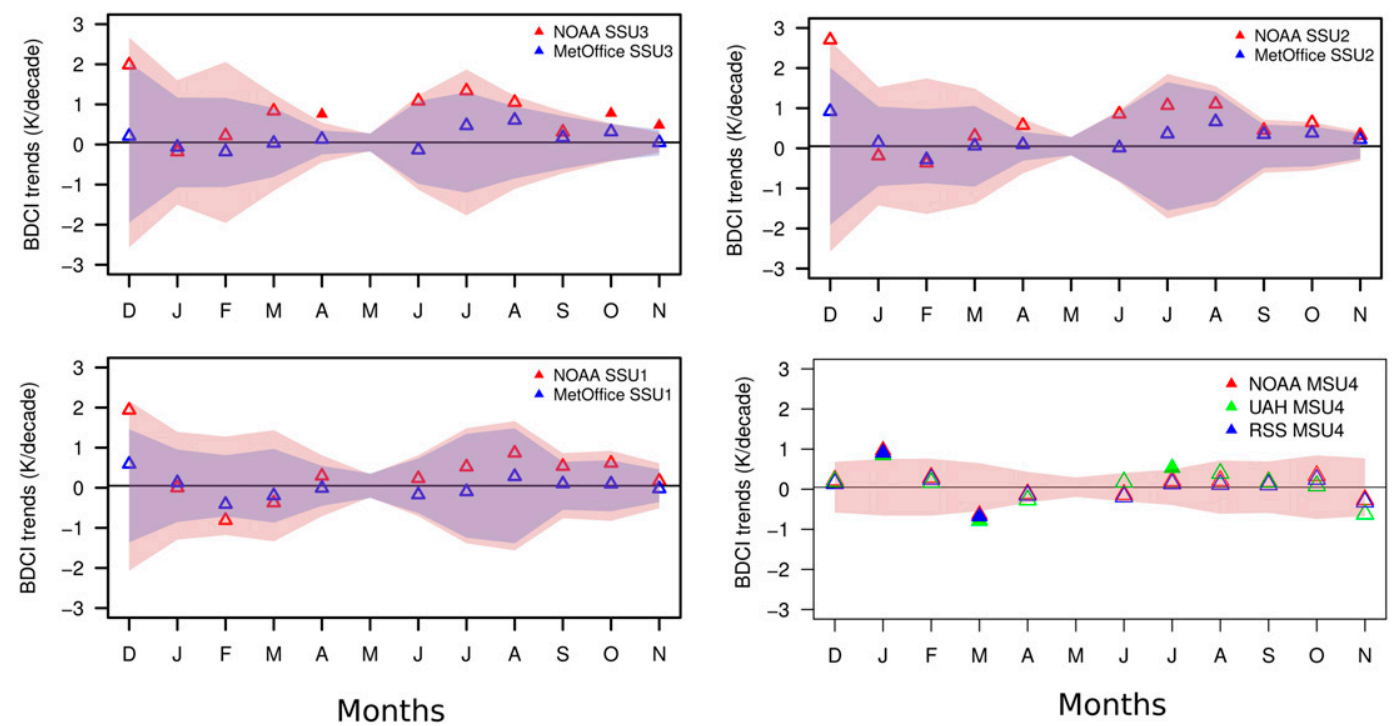

FIG. 5. BDCI_T trends as a function of month for the four layers sampled by the MSU4_RSS, MSU4_NOAA, and MSU4_UAH and the NOAA and Met Office SSU products. Time periods used to calculate the trends are 1979-2013 for the MSU4 products and 1979-2005 for the SSU ones. Shaded areas represent the upper and lower 95\% confidence levels of the of the BDCI_T trends for each level and data product. Note that from December to April the BDCI_T trends are computed for the NH and from June to November for the SH. May has been excluded from the analysis because the extratropical temperatures are not well anticorrelated with the tropical ones in either the $\mathrm{NH}$ or the SH. Filled (open) triangles indicate trends that are statistically (not) significant at the $95 \%$ confidence level.

acceleration of the SH branch of the BDC. Nevertheless they stated that the trends in the nonadjusted BDCI_T are not statistically significant. Here we argue that trends in the BDC should be examined with the nonadjusted BDCI_T, and we do not conclude that there has been an acceleration of the BDC over the depth of the stratosphere over the last three decades.

Fu et al. (2010) argue that MSU4 temperature trends for the period 1980-2008 are consistent with a significant acceleration of the BDC from June to November in the $\mathrm{SH}$ and from December to February in the NH. They also show that the trends are consistent with a weakening of the BDC during March. Our analysis of the MSU4 temperatures reproduces the main features found by $\mathrm{Fu}$ et al. (2010): strong warming over NH pole cap during December-January followed by a strong cooling juxtaposed against subtropical warming during March. Nevertheless, here we argue that if a trend in the BDC exists, it should also be apparent in the trends of the $T^{*}$ field [Eq. (2)] and not only in trends from $\bar{T}$ [Eq. (1)]. Our zonal $T^{*}$ trends are not statistically significant at the $95 \%$ confidence level and moreover the high-latitude warming areas both in the $\mathrm{NH}$ and in the $\mathrm{SH}$ are not linked with any tropical cooling. Presumably, direct radiative forcing associated with the $\mathrm{CO}_{2}$ concentration increase has only induced cooling at stratosphere levels over the last three decades (Ramaswamy et al. 2001; Shine et al. 2003). Hence, if there were a positive trend in tropical upwelling, we would also expect to find cooling in the tropics when removing the temperature global mean anomalies from our zonal time series since the trends in the global mean are negative. Therefore, unlike Fu et al. (2010), our MSU4 trends are not consistent with an acceleration of the BDC over the last three decades in the lower stratosphere. Even so, an acceleration of the $\mathrm{NH}$ lower branch of the BDC cannot be completely discarded because the MSU4 weighting function contains part of the upper troposphere that has warmed up during the last decades, possibly masking the lower-stratosphere tropical cooling.

\section{b. Temperature trends in radiosonde datasets}

Radiosondes are an invaluable source of temperature data. To assess the robustness of the observed trend structure, we computed trends for the RICH and RATPAC radiosonde datasets that by construction are almost completely independent of satellite radiances.

We have analyzed trends in $T^{*}$ as a function of month and latitude at three individual pressure levels from 70 to $30 \mathrm{hPa}$, so mainly covering the lower and midstratosphere for the period 1979-2013 (Fig. 6) and for the entire time period covered by radiosonde datasets 
RATPAC

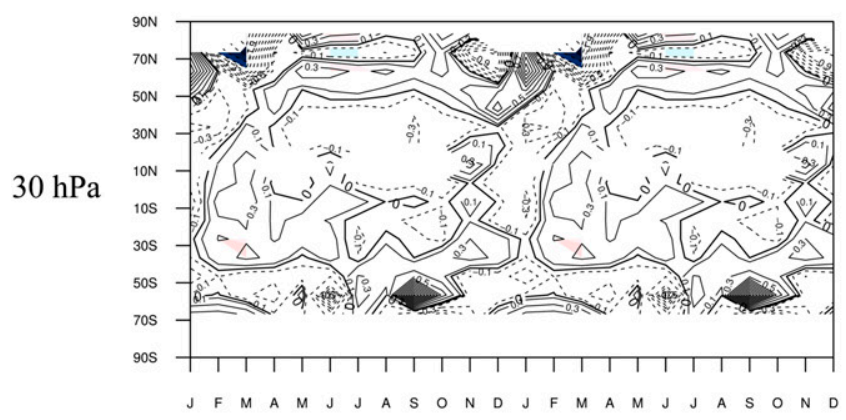

$50 \mathrm{hPa}$

$70 \mathrm{hPa}$
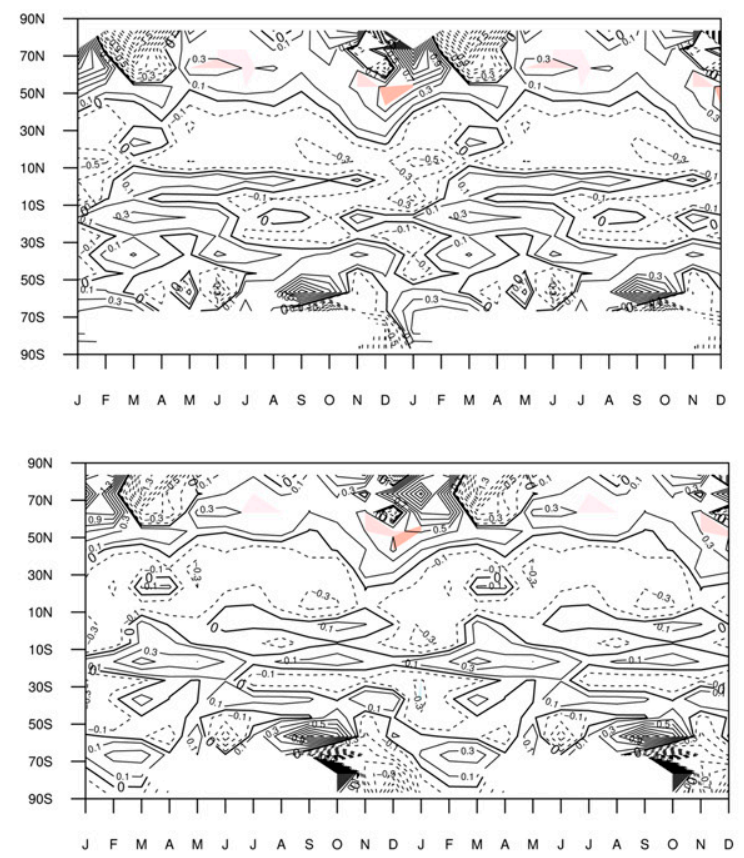

Months
$\mathrm{RICH}$

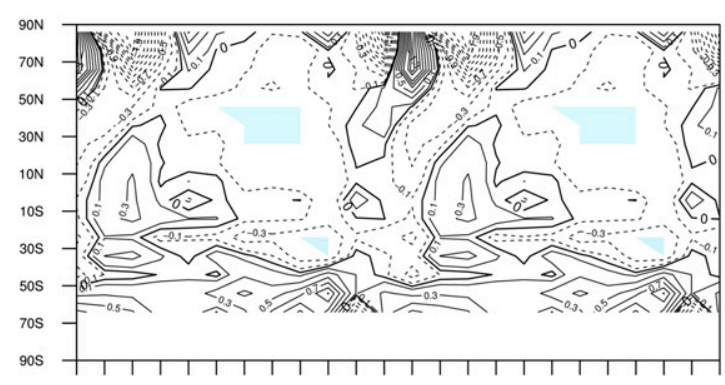

J $F$ M A M J J A S $\quad$ O $N$ D J J F $M$ M A M J J A

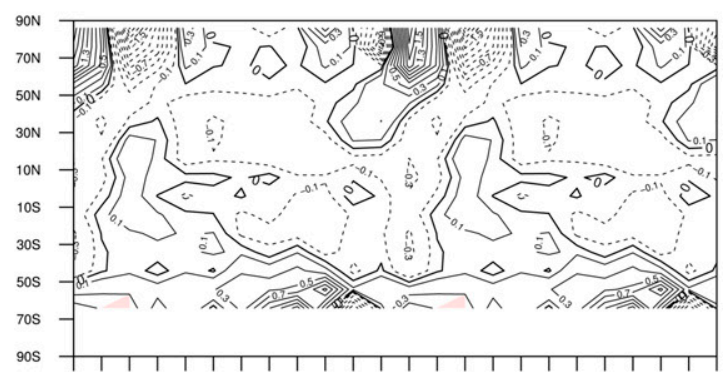

$J F$ J A M J J A $S$ S $O$ N

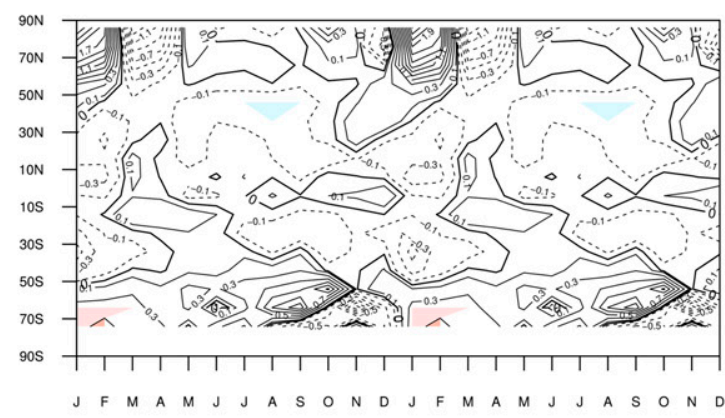

Months

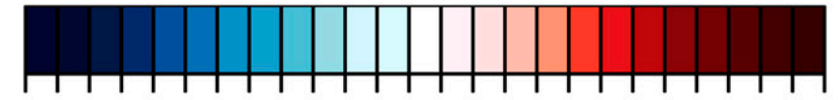

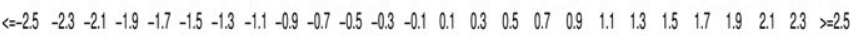

\section{K/decade}

FIG. 6. Zonal-mean $T^{*}$ trends for the period 1979-2013 as a function of month and latitude at (top)-(bottom) three pressure levels sampled by (left) RATPAC and (right) RICH radiosonde products. Non-filled areas indicate that no data are available over this latitude for the month considered. Note that we show two complete yearly cycles for clarity.

1958-2013 (Fig. 7). Radiosonde data have a limited and irregular spatial coverage everywhere except at $\mathrm{NH}$ midlatitudes, and the sparse longitudinal distribution can bias some latitudinal bands to certain longitudes. Despite that, both RATPAC and RICH datasets reasonably reproduce the pattern and magnitude of temperature trends for the MSU4 and NOAA SSU1, although the structures are noisier, especially for
RATPAC data due to the irregular spatial distribution. At 50 and $70 \mathrm{hPa}$ both RATPAC and RICH show extended cooling in the tropics juxtaposed against warming in the $\mathrm{NH}$ polar cap and against warming in the $\mathrm{SH}$ high latitudes during late spring, although none of these trends is statistically significant at the $95 \%$ confidence level. The cooling observed in March is also well reproduced at 50 and $70 \mathrm{hPa}$ for both datasets. The trend 
RATPAC

$30 \mathrm{hPa}$

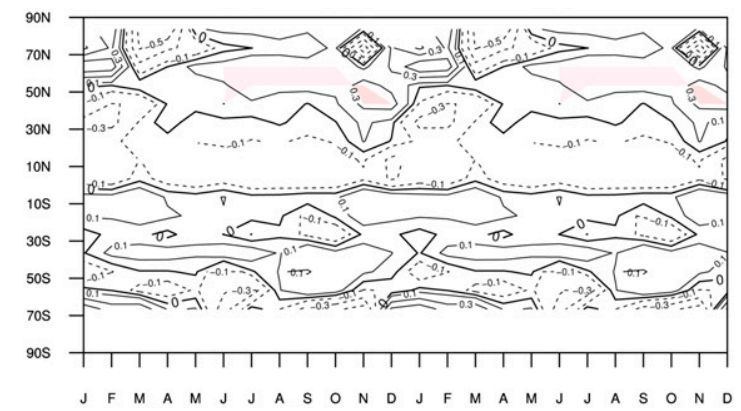

$50 \mathrm{hPa}$

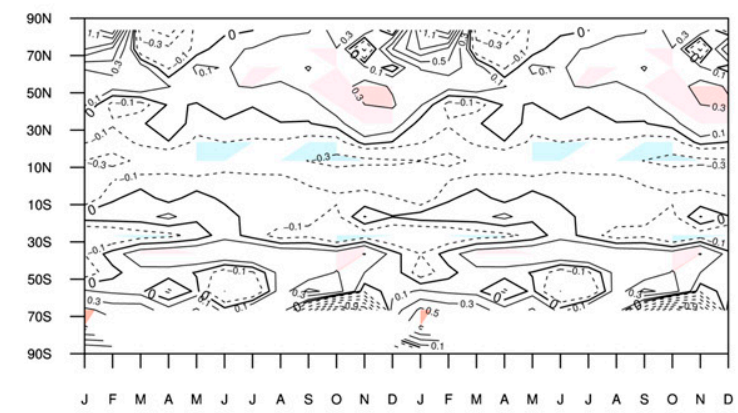

$70 \mathrm{hPa}$

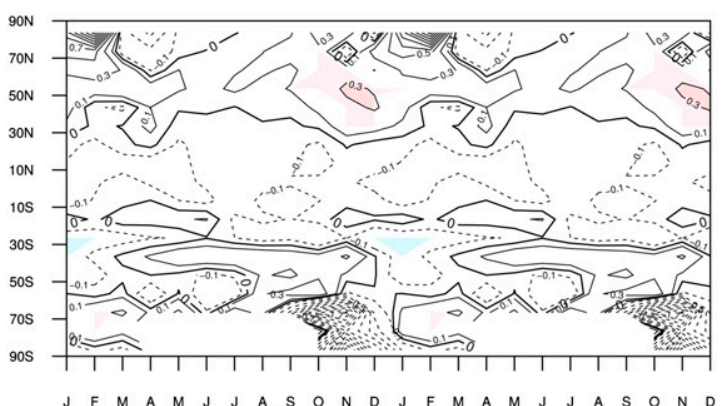

Months
$\mathrm{RICH}$
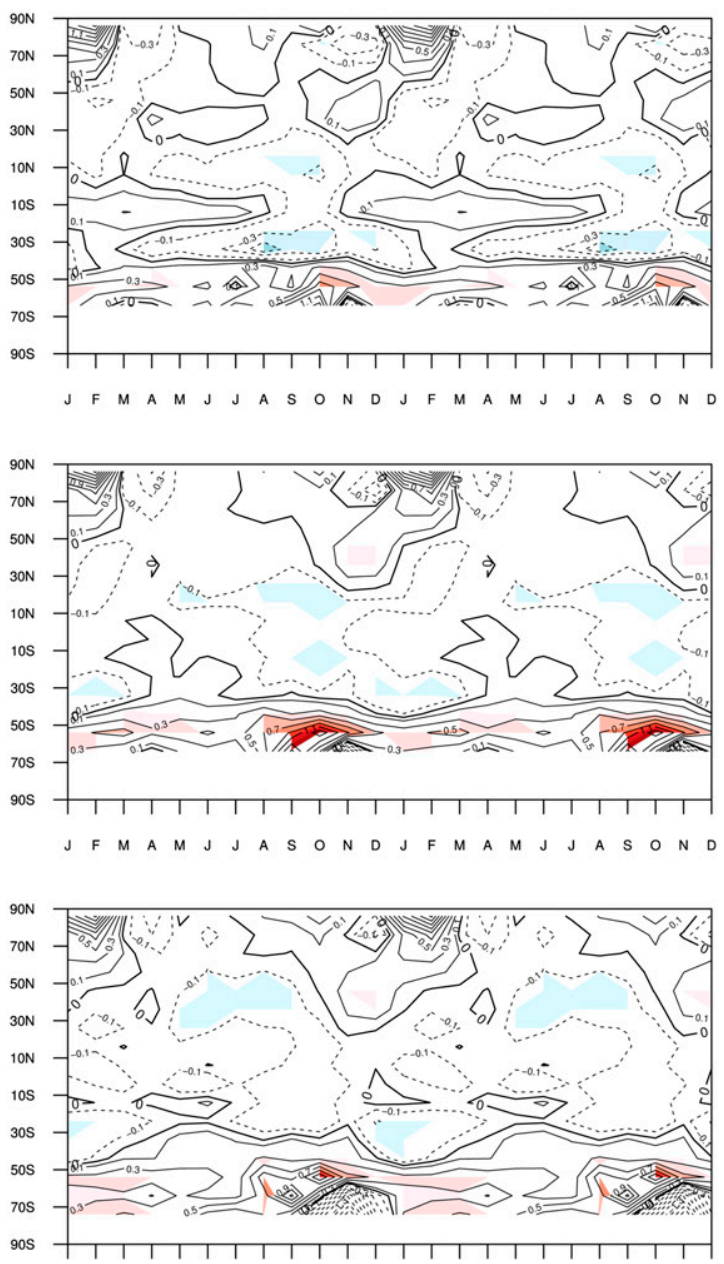

J F M A M J J A S O N D J F M A M J J A S O N D

Months

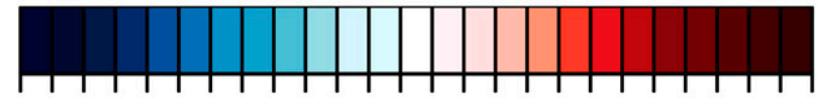

$\left\langle\begin{array}{lllllllllllllllllllllllllllllll}-2.5 & -2.3 & -2.1 & -1.9 & -1.7 & -1.5 & -1.3 & -1.1 & -0.9 & -0.7 & -0.5 & -0.3 & -0.1 & 0.1 & 0.3 & 0.5 & 0.7 & 0.9 & 1.1 & 1.3 & 1.5 & 1.7 & 1.9 & 2.1 & 2.3 & >=2.5\end{array}\right.$

\section{K/decade}

FIG. 7. As in Fig. 6, but for the period 1958-2013.

pattern calculated for the entire time period (19582013) (Fig. 7) resembles the 1979-2013 one but the magnitudes of the high-latitude warming trends are smaller. This indicates that high-latitude warming is concentrated at the end of the time series.

Similar results were found by Young et al. (2011) using IUK radiosonde data at $30 \mathrm{hPa}$. In the $\mathrm{SH}$, the ozone-induced cooling in late spring is well reproduced for RICH data, which has better coverage than RATPAC in the SH high latitudes. The largest discrepancies between radiosonde datasets are detected in $\mathrm{SH}$ high latitudes during spring when a strong warming at $100 \mathrm{hPa}$ is observed in RATPAC but not in RICH radiosondes. The sampling longitude bias in the binned means, as well as the individual adjustment procedures, might be responsible for these differences.

Figure 8 displays the BDCI_T trends and the upper and lower $95 \%$ confidence levels of the BDCI_T trends (shaded region) for the RATPAC and RICH datasets. RATPAC shows positive and statistically significant 

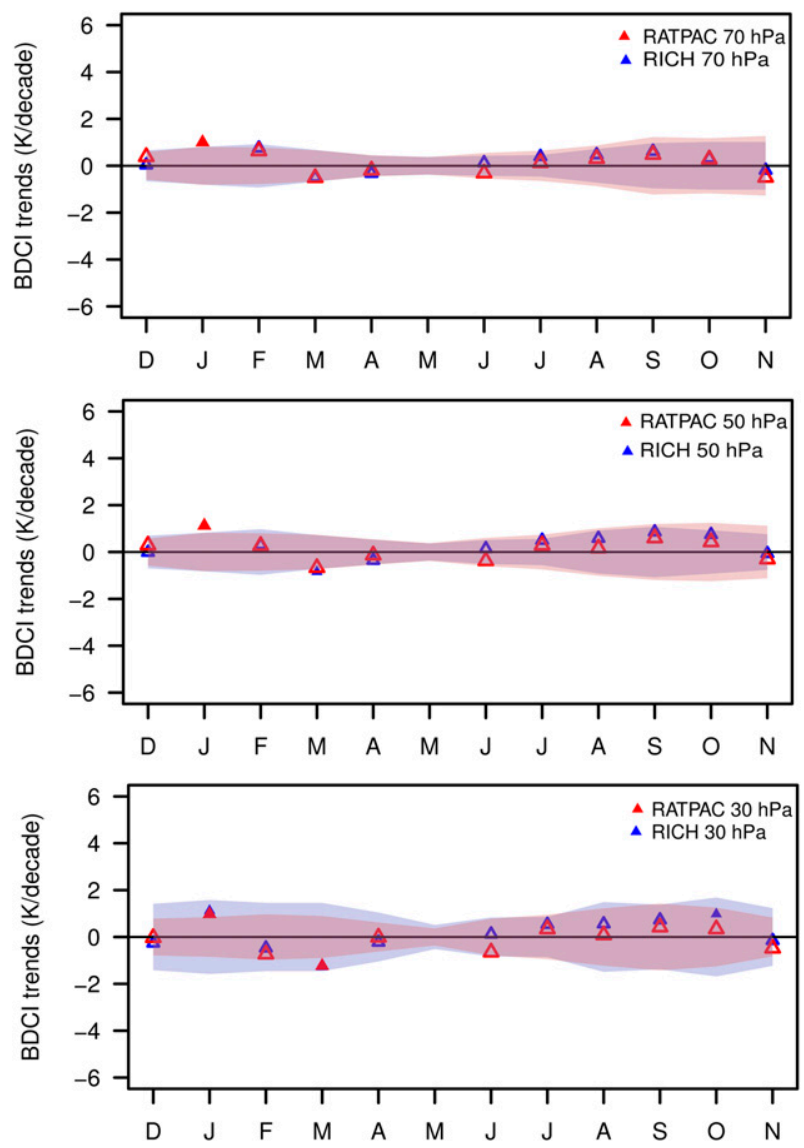

FIG. 8. As in Fig. 5, but for BDCI_T trends as a function of month for the three layers sampled by RATPAC and RICH radiosonde products. The time period used to calculate the trends is $1979-2013$.

trends on the order of $3 \mathrm{~K}$ decade $^{-1}$ during December and January at 50 and $30 \mathrm{hPa}$ and from December to February at $70 \mathrm{hPa}$; this indicates a possible acceleration of the lower branch of the BDC in the $\mathrm{NH}$ in winter months. RICH also exhibits a positive and significant BDCI_T trend in December at 50 and $70 \mathrm{hPa}$ although the magnitude is weaker compared with RATPAC. All three RATPAC levels show positive and significant BDCI_T trends in April on the order of $2 \mathrm{~K} \mathrm{decade}^{-1}$ that are not reproduced by RICH. In the SH, RATPAC is characterized by a very large variance due to the sparse radiosonde coverage. The process of homogenization in RICH largely reduces the variance in the $\mathrm{SH}$ but, as is the case for RATPAC, the BDCI_T does not show any significant trend for any month.

\section{Summary}

In this paper we present an updated and extended analysis of trends in stratospheric temperatures from multiple satellite retrievals and two radiosonde products to determine if they are consistent with a strengthening of the BDC during the past three decades. The estimated trends in the BDC are weak in all datasets and are not statistically significant at the $95 \%$ threshold. Moreover, there are large discrepancies between different observational products.

Large discrepancies are found between BDC trends derived from the NOAA and Met Office SSU temperature retrievals. While the three NOAA-SSU channels all show extended tropical cooling juxtaposed against warming both in the $\mathrm{NH}$ and in the $\mathrm{SH}$ polar regions during December and during SH winter, respectively, the Met Office-SSU retrieval only shows a weak cooling for ch2 during December juxtaposed with weaker highlatitude warming. Both the Met Office and NOAA are working on new versions of the SSU dataset that should address these large discrepancies; see, for example, the recent recalibration of the SSU radiances by Zou et al. (2014).

The distinct methodology we used in this work lead to results that differ from previous studies that found Met Office, MSU4, and radiosonde temperature anomalies to be consistent with a statistically significant acceleration of the BDC during the boreal winter. While all of those studies infer trends in the BDC from zonal mean temperature anomalies, we examine all temperature trends as "departures" from the global mean [Eq. (1)]. Presumably, trends in the departure temperature field $\left(T^{*}\right)$ are not strongly affected by trends due to wellmixed greenhouse gases and hence they mainly respond to changes in dynamics (BDC). Therefore, any trend in the BDC should be projected into the $T^{*}$ field.

In the light of the discrepancies between observations of stratospheric temperatures, we conclude that it is essential to better constrain the accuracy of these observational datasets if we want to monitor the strengthening of the BDC that is predicted by most of the models for the twenty-first century in response to GHG-induced climate change.

Acknowledgments. This work was partially supported by the Spanish Ministry of Economy and Competitiveness through the project CGL2012-38945. We are grateful to David Thompson (Colorado State University) for several contributions and comments throughout the text. We are also grateful to Paul Young (NOAA ESRL/CIRES CU-Boulder) for comments and suggestions on the text and to Rolando Garcia (UCAR/ NCAR) for supplying the WACCM TEM diagnosis. We are also grateful to three anonymous reviewers for useful comments and suggestions that helped to improve the present work. Finally, authors would like to thank all 
the agencies responsible for the production and distribution of the data used in this analysis (outlined in the text).

\section{REFERENCES}

Andrews, D. G., J. R. Holton, and C. B. Leovy, 1987: Middle Atmosphere Dynamics. Academic Press, 487 pp.

Austin, J., 2002: A three-dimensional coupled chemistryclimate model simulation of past stratospheric trends. J. Atmos. Sci., 59, 218-232, doi:10.1175/1520-0469(2002)059<0218: ATDCCC $>2.0 . \mathrm{CO} ; 2$.

— of the Brewer-Dobson circulation and the age of stratospheric air. Geophys. Res. Lett., 33, L17807, doi:10.1029/ 2006 GL026867.

_ - J. Wilson, F. Li, and H. Vömel, 2007: Evolution of water vapor concentrations and stratospheric age of air in coupled chemistry-climate model simulations. J. Atmos. Sci., 64, 905921, doi:10.1175/JAS3866.1.

Birner, T., and H. Bönisch, 2011: Residual circulation trajectories and transit times into the extratropical lowermost stratosphere. Atmos. Chem. Phys., 11, 817-827, doi:10.5194/acp-11-817-2011.

Brewer, A. W., 1949: Evidence for a world circulation provided by the measurements of helium and water vapour distribution in the stratosphere. Quart. J. Roy. Meteor. Soc., 75, 351-363, doi:10.1002/ qj. 49707532603 .

Butchart, N., 2014: The Brewer-Dobson circulation. Rev. Geophys., 52, 157-184, doi:10.1002/2013RG000448.

, and A. A. Scaife, 2001: Removal of chlorofluorocarbons by increased mass exchange between the stratosphere and troposphere in a changing climate. Nature, 410, 799-802, doi:10.1038/35071047.

_- and Coauthors, 2006: Simulations of anthropogenic change in the strength of the Brewer-Dobson circulation. Climate Dyn., 27, 727-741, doi:10.1007/s00382-006-0162-4.

_ - and Coauthors, 2010: Chemistry-climate model simulations of twenty-first century stratospheric climate and circulation changes. J. Climate, 23, 5349-5374, doi:10.1175/2010JCLI3404.1.

Calvo, N., and R. R. Garcia, 2009: Wave forcing of the tropical upwelling in the lower stratosphere under increasing concentrations of greenhouse gases. J. Atmos. Sci., 66, 3184-3196, doi:10.1175/ 2009JAS3085.1.

Christy, J. R., R. W. Spencer, W. B. Norris, W. D. Braswell, and D. E. Parker, 2003: Error estimates of version 5.0 of MSUAMSU bulk atmospheric temperatures. J. Atmos. Oceanic Technol., 20, 613-629, doi:10.1175/1520-0426(2003)20<613: EEOVOM $>2.0 . \mathrm{CO} ; 2$.

Cook, P. A., and H. K. Roscoe, 2009: Variability and trends in stratospheric $\mathrm{NO}_{2}$ in Antarctic summer, and implications for stratospheric $\mathrm{NO}_{\mathrm{y}}$. Atmos. Chem. Phys., 9, 3601-3612, doi:10.5194/ acp-9-3601-2009.

Dee, D. P., and Coauthors, 2011: The ERA-Interim reanalysis: Configuration and performance of the data assimilation system. Quart. J. Roy. Meteor. Soc., 137, 553-597, doi:10.1002/qj.828.

Dobson, G. M. B., 1956: Origin and distribution of the polyatomic molecules in the atmosphere. Proc. Roy. Soc. London, 236A, 187-193, doi:10.1098/rspa.1956.0127.

_ D. N. Harrison, and J. Lawrence, 1929: Measurements of the amount of ozone in the Earth's atmosphere and its relation to other geophysical conditions. Proc. Roy. Soc. London, 122A, 456-486, doi:10.1098/rspa.1929.0034.
Durre, I., R. S. Vose, and D. B. Wuertz, 2006: Overview of the Integrated Global Radiosonde Archive. J. Climate, 19, 53-68, doi:10.1175/JCLI3594.1.

Engel, A., and Coauthors, 2009: Age of stratospheric air unchanged within uncertainties over the past 30 years. Nat. Geosci., 2, 28-31, doi:10.1038/ngeo388.

Eyring, V., T. G. Shepherd, and D. W. Waugh, Eds., 2010: SPARC report on the evaluation of chemistry-climate models. SPARC Rep. 5, WCRP-132, WMO/TD-1526, 434 pp. [Available online at http://www.atmosp.physics.utoronto.ca/ SPARC/ccmval_final/.]

Free, M., D. J. Seidel, J. K. Angell, J. Lanzante, I. Durre, and T. C. Peterson, 2005: Radiosonde Atmospheric Temperature Products for Assessing Climate (RATPAC): A new data set of large-area anomaly time series. J. Geophys. Res., 110, D22101, doi:10.1029/2005JD006169.

Fu, Q., S. Solomon, and P. Lin, 2010: On the seasonal dependence of tropical lower-stratospheric temperature trends. Atmos. Chem. Phys., 10, 2643-2653, doi:10.5194/acp-10-2643-2010.

Garcia, R. R., and W. J. Randel, 2008: Acceleration of the BrewerDobson circulation due to increases in greenhouse gases. J. Atmos. Sci., 65, 2731-2739, doi:10.1175/2008JAS2712.1.

, D. R. Marsh, D. E. Kinnison, B. A. Boville, and F. Sassi, 2007: Simulation of secular trends in the middle atmosphere, 19502003. J. Geophys. Res., 112, D09301, doi:10.1029/2006JD007485.

Garny, H., M. Dameris, W. Randel, G. E. Bodeker, and R. Deckert, 2011: Dynamically forced increase of tropical upwelling in the lower stratosphere. J. Atmos. Sci., 68, 12141233, doi:10.1175/2011JAS3701.1.

Haimberger, L., C. Tavolato, and S. Sperka, 2012: Homogenization of the global radiosonde temperature dataset through combined comparison with reanalysis background series and neighboring stations. J. Climate, 25, 8108-8131, doi:10.1175/ JCLI-D-11-00668.1.

Haynes, P. H., C. J. Marks, M. E. McIntyre, T. G. Shepherd, and K. P. Shine, 1991: On the "downward control" of extratropical diabatic circulations by eddy-induced mean zonal forces. J. Atmos. Sci., 48, 651-678, doi:10.1175/1520-0469(1991)048<0651: OTCOED $>2.0 . \mathrm{CO} ; 2$.

Hegglin, M. I., and T. G. Shepherd, 2009: Large climate-induced changes in ultraviolet index and stratosphere-to-troposphere flux. Nat. Geosci., 2, 687-691, doi:10.1038/ngeo604.

Holton, J. R., P. H. Haynes, M. E. McIntyre, A. R. Douglass, R. B. Rood, and L. Pfister, 1995: Stratosphere-troposphere exchange. Rev. Geophys., 33, 403-439, doi:10.1029/95RG02097.

Iwasaki, T., H. Hamada, and K. Miyazaki, 2009: Comparisons of Brewer-Dobson circulations diagnosed from reanalyses. J. Meteor. Soc. Japan, 87, 997-1006, doi:10.2151/jmsj.87.997.

Li, F., J. Austin, and J. Wilson, 2008: The strength of the BrewerDobson circulation in a changing climate: Coupled chemistryclimate model simulations. J. Climate, 21, 40-57, doi:10.1175/ 2007JCLI1663.1.

Lin, P., and Q. Fu, 2013: Changes in various branches of the Brewer-Dobson circulation from an ensemble of chemistry climate models. J. Geophys. Res., 118, 73-84, doi:10.1029/ 2012JD018813.

$\longrightarrow,-$, S. Solomon, and J. M. Wallace, 2009: Temperature trend patterns in Southern Hemisphere high latitudes: Novel indicators of stratospheric change. J. Climate, 22, 6325-6341, doi:10.1175/2009JCLI2971.1.

McLandress, C., and T. G. Shepherd, 2009: Simulated anthropogenic changes in the Brewer-Dobson circulation, including its 
extension to high latitudes. J. Climate, 22, 1516-1540, doi:10.1175/ 2008JCLI2679.1.

Mears, C. A., and F. J. Wentz, 2009: Construction of the Remote Sensing Systems V3.2 atmospheric temperature records from the MSU and AMSU microwave sounders. J. Atmos. Oceanic Technol., 26, 1493-1509, doi:10.1175/2009JTECHA1237.1.

Nash, J., 1988: Extension of explicit radiance observations by the Stratospheric Sounding Unit into the lower stratosphere and lower mesosphere. Quart. J. Roy. Meteor. Soc., 114, 11531171, doi:10.1002/qj.49711448213.

, and G. F. Forrester, 1986: Long-term monitoring of stratospheric temperature trends using radiance measurements obtained by the TIROS-N series of NOAA spacecraft. $A d v$. Space Res., 6, 37-44, doi:10.1016/0273-1177(86)90455-2.

Plumb, R. A., 2002: Stratospheric transport. J. Meteor. Soc. Japan, 80, 793-809, doi:10.2151/jmsj.80.793.

Ramaswamy, V., and Coauthors, 2001: Stratospheric temperature trends: Observations and model simulations. Rev. Geophys., 39, 71-122, doi:10.1029/1999RG000065.

Randel, W. J., and F. Wu, 1999: A stratospheric ozone trends data set for global modeling studies. Geophys. Res. Lett., 26, 3089 3092, doi:10.1029/1999GL900615.

_ - and Coauthors, 2009: An update of observed stratospheric temperature trends. J. Geophys. Res., 114, D02107, doi:10.1029/ 2008JD010421.

Ray, E. A., and Coauthors, 2010: Evidence for changes in stratospheric transport and mixing over the past three decades based on multiple data sets and tropical leaky pipe analysis. J. Geophys. Res., 115, D21304, doi:10.1029/2010JD014206.

Rind, D., R. Suozzo, N. K. Balachandran, and M. J. Prather, 1990: Climate change and the middle atmosphere, Part I: The doubled $\mathrm{CO}_{2}$ climate. J. Atmos. Sci., 47, 475-494, doi:10.1175/ 1520-0469(1990)047<0475:CCATMA > 2.0.CO;2.

Rosenlof, H. K., 1995: Seasonal cycle of the residual mean meridional circulation in the stratosphere. J. Geophys. Res., 100, 5173-5191, doi:10.1029/94JD03122.

Santer, B. D., T. M. L. Wigley, J. S. Boyle, D. J. Gaffen, J. J. Hnilo, D. Nychka, D. E. Parker, and K. E. Taylor, 2000: Statistical significance of trends and trend differences in layer-average atmospheric temperature time series. J. Geophys. Res., 105 (D6), 7337-7356, doi:10.1029/1999JD901105.

Seviour, W. J. M., N. Butchard, and S. C. Hardiman, 2012: The Brewer-Dobson circulation inferred from ERA-Interim. Quart. J. Roy. Meteor. Soc., 138, 878-888, doi:10.1002/qj.966.

Shepherd, T. G., 2008: Dynamics, stratospheric ozone, and climate change. Atmos.-Ocean, 46, 117-138, doi:10.3137/ao.460106.

Sherwood, S. C., C. L. Meyer, R. J. Allen, and H. A. Titchner, 2008: Robust tropospheric warming revealed by iteratively homogenized radiosonde data. J. Climate, 21, 5336-5352, doi:10.1175/2008JCLI2320.1.

Shine, K. P., and Coauthors, 2003: A comparison of modelsimulated trends in stratospheric temperatures. Quart. J. Roy. Meteor. Soc., 129, 1565-1588, doi:10.1256/qj.02.186.
_ J. J. Barnett, and W. J. Randel, 2008: Temperature trends derived from Stratospheric Sounding Unit radiances: The effect of increasing $\mathrm{CO}_{2}$ on the weighting function. Geophys. Res. Lett., 35, L02710, doi:10.1029/2007GL032218.

Sigmond, M., P. C. Siegmund, E. Manzini, and H. Kelder, 2004: A simulation of the separate climate effects of middle-atmospheric and tropospheric $\mathrm{CO}_{2}$ doubling. J. Climate, 17, 2352-2367, doi:10.1175/1520-0442(2004)017<2352:ASOTSC>2.0.CO;2.

Solomon, S., 1999: Stratospheric ozone depletion: A review of concepts and history. Rev. Geophys., 37, 275-316, doi:10.1029/ 1999RG900008.

Thompson, D. W. J., and S. Solomon, 2009: Understanding recent stratospheric climate change. J. Climate, 22, 1934-1943, doi:10.1175/ 2008JCLI2482.1.

- and Coauthors, 2012: The mystery of recent stratospheric temperature trends. Nature, 491, 692-697, doi:10.1038/nature11579.

Ueyama, R., and J. M. Wallace, 2010: To what extent does highlatitude wave forcing drive tropical upwelling and the BrewerDobson circulation? J. Atmos. Sci., 67, 1232-1246, doi:10.1175/ 2009JAS3216.1.

Wang, L., C.-Z. Zou, and H. Qian, 2012: Construction of stratospheric temperature data records from stratospheric sounding units. J. Climate, 25, 2931-2946, doi:10.1175/JCLI-D-11-00350.1.

WMO, 2011: Scientific Assessment of Ozone Depletion: 2010. Global Ozone Research and Monitoring Project Rep. 52, World Meteorological Organization, 511 pp.

— , 2012: Antarctic Ozone Bulletin. World Meteorological Organization. [Available online at http://www.wmo.int/pages/ prog/arep/WMOAntarcticOzoneBulletins2012.html.]

Young, P. J., D. W. J. Thompson, K. H. Rosenlof, S. Solomon, and J.-F. Lamarque, 2011: The seasonal cycle and interannual variability in stratospheric temperatures and links to the Brewer-Dobson circulation: An analysis of MSU and SSU data. J. Climate, 24, 6243-6258, doi:10.1175/ JCLI-D-10-05028.1.

- K. H. Rosenlof, S. Solomon, S. C. Sherwood, Q. Fu, and J.-F. Lamarque, 2012: Changes in stratospheric temperatures and their implications for changes in the Brewer-Dobson circulation, 1979-2005. J. Climate, 25, 1759-1772, doi:10.1175/ 2011JCLI4048.1.

Yulaeva, E., J. Holton, and J. M. Wallace, 1994: On the cause of the annual cycle in tropical lower-stratospheric temperatures. J. Atmos. Sci., 51, 169-174, doi:10.1175/1520-0469(1994)051<0169: OTCOTA $>2.0 . \mathrm{CO} ; 2$.

Zou, C.-Z., M. D. Goldberg, Z. Cheng, N. C. Grody, J. T. Sullivan, C. Cao, and D. Tarpley, 2006: Recalibration of microwave sounding unit for climate studies using simultaneous nadir overpasses. J. Geophys. Res., 111, D19114, doi:10.1029/ 2005JD006798.

—, H. Qian, W. Wang, L. Wang, and C. Long, 2014: Recalibration and merging of SSU observations for stratospheric temperature trend studies. J. Geophys. Res. Atmos., 119, 13 180-13205, doi:10.1002/2014JD021603. 